\title{
Effect of interaction between different plant growth regulators on in vitro shoot multiplication of Citrus latifolia Tan. (persian lime)
} Firoozeh Chamandoosti

\author{
Iranian Research Institute of Plant Protection, Agricultural Research, Education and Extension Organization (AREEO), \\ Tehran, Iran
}

$\mathrm{PhD}$ of Cellular and Developmental Biology, Assistant Professor of Iranian Research Institute of Plant Protection Department of Plant Diseases

\begin{abstract}
In this paper a shoot multiplication is described for Citrus latifolia Tan. (persian lime) using nodal segment explants of young one - old - year trees by two different pathways contain with and without callusing phase. The best result for multiple shoot formation and regenerated shoot formation was 3.2 and 2.6 shoots per explants with $4.44 \mu M$ BA plus $0.053 \mu M N A A$ and $4.44 \mu M$ BA plus $0.049 \mu$ M IBA respectively. Alike shoot regeneration, shoot elongation was occurred in medium with $4.44 \mu M B A$ and $0.049 \mu M$ IBA. Micropropagated and regenerated plants are under other experiments.
\end{abstract}

Abbreviation: BA - 6 benzylaminopurine; IBA - Indole acetic acid; NAA - Naphtalene acetic acid; PGRs - Plant Growth Regulators.

Key Words: Persian lime; plant growth regulators; shoot multiplication.

\section{INTRODUCTION}

Accordant worldwide Citrus species are the most widely grown fruit crops in Iran. They contain vitamin C that is very useful for human nutrition. Also their fruits are important source of volatile oils, limonene, $\alpha$-terpinene, $\beta$-terpinene, citral cumarins, bioflavonoids, vitamins, and mucilage (Rathore et al., 2006). Beside apples and bananas, Citrus fruits are the most important fruit crops (FAO 2001). Also it is clear that the sustainable development of the Citrus industry is mainly dependent on a continuous supply of new and improved cultivars (Perez - Tornero et al., 2010). For the Citrus industry to improve fruit quality and reduce biotic and abiotic stresses are major breeding objectives at any time (Wenwu et al., 2007). Citrus varieties are propagated by both sexual and asexual methods. Generally, rootstocks are propagated sexually through seeds, while most of the commercial varieties are propagated by various asexual methods (Chaudhary 1994). These conventional techniques are also not free from risk of perpetuating in-born pathogens. However in vitro micropropagation technology can overcome some constraints to Citrus improvement and cultivation, and can increase fruit quality and resistance to diseases and environmental stresses (Gresser 1994). Also micropropagation systems with high multiplication rates are not only an important asexual method that can be used for the production of clonal plants, but also form the basis for the introduction of genetic variation by genetic transformation or mutagenesis. The genetic transformation of Citrus has been widely studied as a tool to generate transgenic plants with enhanced tolerance of biotic (Cardoso et al., 2010; He et al., 2011 and Ali et al., 2012) and/or abiotic stresses (Bunnag and Tangpong 2012). In both cases, is necessary to be able to regenerate viable shoots, which can be propagated, by either organogenesis or somatic embryogenesis (Perez - Tornero et al., 2010).

In this paper a protocol for cloning of Citrus latifolia Tan. (persian lime) using nodal explant was described. It should be noted that according to Iranian researchers that used graft inoculation and PCR methods, persian lime was tolerant to Candidatus Phytoplasma aurantifolia. Candidatus Phytoplasma aurantifolia is a serious threat to lime and other susceptible Citrus trees in southern Iran (Salehi et al., 2005).

\section{MATERIAL AND METHODS}

This study was conducted in Iranian Research Institute of Plant Protection Department of Plant Diseases, Tehran - Iran Young trees of Citrus latifolia Tan. (persian lime) were collected from Jahrom Citrus nursery, Jahrom - Fars - Iran

\subsection{Surface sterilization and plant material preparation}

One - old - year young tree persian lime (Citrus latifolia Tan.) were used as the source of explants from their nodal segments. 30 - 35 - old - day new shoots measuring $12-15 \mathrm{~cm}$ in length with $4-6$ nods were cut and collected in plastic bag and transferred to the laboratory from greenhouse for experiments. 


\subsection{Preparation and sterilization of explants}

After defoliation of shoots, and cutting $0.5-0.7 \mathrm{~cm}$ in length nodal segments (explants) surface sterilized under laminar air flow with dipping in $25 \%$ hypochlorite sodium for $5 \mathrm{~min}$. Then were rinsed in distilled water $4-5$ times.

\subsection{Culture media}

Culture media consisted of MS (Murashig and Skoog 1962) salts and vitamins plus 3\% sucrose that were solidified with 0.75 $\%$ agar agar. Also the media were supplemented with BA $(0-8.88 \mu \mathrm{M}), 0.053 \mu \mathrm{M}$ NAA and $0.049 \mu \mathrm{M}$ IBA. The pH of media was adjusted to 5.8 before gelling with $1 \mathrm{~N} \mathrm{NaOH}$ or $\mathrm{HCl}$ and after gelling autoclaved for 20 min at $121^{\circ} \mathrm{C}$. Then the media dispensed into $9-\mathrm{cm}$ diameter petri dishes. The culture was incubated at $25 \pm 2^{\circ} \mathrm{C}$ and under $16-\mathrm{h}$ photoperiod.

\subsection{Experimental design and data analysis}

Experiments were conducted in a completely randomized design with 4 replicates and 5 explants per replicate. The mean number of multiplicated shoots per explants and the mean length of multiplicated shoots assay carried out on MS media with 12 combinations of cytokinin (BA) and auxins (NAA and IBA). Data were analysised by Dunkan Multiple Range Test.

\section{RESULTS AND DISCUSSION}

Shoot multiplication in the presence of media with different concentrations of BA and $0.053 \mu \mathrm{M}$ NAA and or $0.049 \mu \mathrm{M}$ IBA compared after nearly 4 weeks of culture. It can be seen that the highest number of multiplicated shoots (3.2) per explants was observed in the media containing $4.44 \mu \mathrm{M} \mathrm{BA}$ and $0.053 \mu \mathrm{M}$ NAA (Fig. 1and Fig. 5). Also the highest length of shoot $(10 \mathrm{~cm}$ ) was obtained on medium with $4.44 \mu \mathrm{M} \mathrm{BA}$ and $0.049 \mu \mathrm{M}$ IBA (Fig. 3 and Fig. 6). It is interesting that in these study observations such as shoot multiplication and growth of shoot (longitudinal growth and foliation) were affected by interaction between different plant growth regulators more rather than plant growth regulators solely. There are reports about positive effect of increasing concentration of BA on shoot multiplication. For example Mehdi Farshad and coworkers in 2014 resulted that BAP alone (from $8.8 \mu \mathrm{M}$ to $26.6 \mu \mathrm{M}$ ) was significantly effective on shoot multiplication in Chlorophytum borivilianum. However there are reports that show shoot proliferation decreased with increasing concentration of BA alone (Komal et al., 2013). This experience is in accordance with ours that frequency of response from nodal explants decreased with a progressive increase in the level of BA [8.88 and $4.44 \mu \mathrm{M} \mathrm{BA}, 4.75-8.20$ ( $\mathrm{cm}$ for length of shoots)] respectively.

As was mentioned earlier, the interaction between plant growths regulators have very important effects on induction of shoots also number of shoot multiplicated. So as was shown in Fig. 2 the mean number of multiplicated shoots on explants increased when BA was used solely $(1.2-2.66$ for $0.044-8.88 \mu \mathrm{M} \mathrm{BA})$. The positive effect of BA on the induction of regenerated shoot is clear. For example the positive effect of BA on shooting in Cucurbita maxima Duch (Lee et al., 2003), Ruta graveolunse L. (Ahmad et al., 2010), tomato (Lycopersicon esculentum L.) (Rai et al., 2012) and Japanese pear (Kadota et al. 2001). These results were somewhat similar to our results about the mean number of multiplicated shoots. However it seams $4.44 \mu \mathrm{M}$ BA either in terms of nature or in terms of level is suitable for shoot multiplication in Citrus genus. So that Al-Khayri and Al-Bahrany in 2001 expressed that Best results for multiple shoot formation, 8 shoots per node, were obtained with $4.44 \mu \mathrm{M}$ BA and $2.32 \mu \mathrm{M}$ kinetin.

Another interesting result of this study is the circumstance of shoot multiplication. As is clear in figures multiplication shoot in the presence of BA and NAA was direct while multiplication shoot in the presence of BA and IBA was indirect and accompanied by callusing phase (Fig.7 and Fig. 8). So the role of interaction between plant growth regulators in in vitro culture of plants is proved again.

Very different and important roles are demonstrated for plant cell, tissue and organ culture. Briefly shoot multiplication and shoot regeneration are two different kind of organogenesis with two different utilizations. This result implies that rapid plant regeneration system which could be used for the somaclonal variation induction are possible for persian lime, on the other hand in vitro propagation through lateral buds proliferation that is an efficient method for large scale production of true - to type planting material of important plant (Doo and Iyyakkannu 2016) is practicable for this valuable plant. It is worth noting that for assessment the level of background genetic changes resulting from the tissue culture processes (Munthali et al. 1996) and to verify the "true-to-type" genotype of micropropagated plants with shoot multiplication and or shoot regeneration DNA-based marker techniques such as RFLPs (Nelke et al., 1993) and or RAPD (Munthali et al., 1996) are necessary (Komal et al., 2013) 


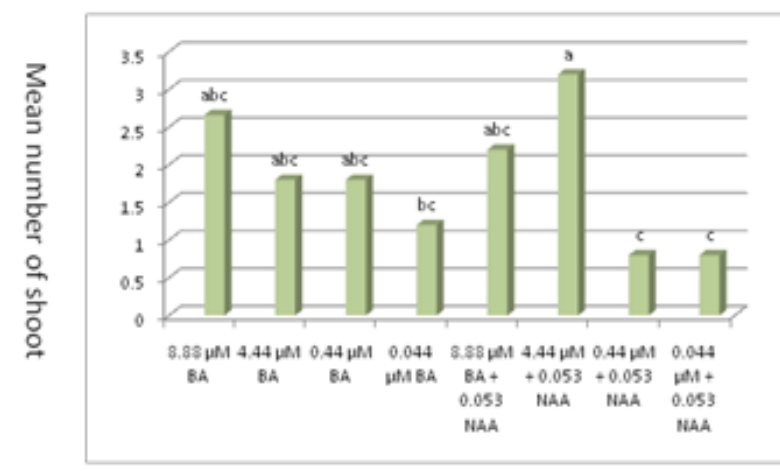

FIG 1. The mean number of multiplicated shoot on medium with $8.88-0.044 \mu \mathrm{M} B A$ and 8.88-0.044 $\mu \mathrm{M}$ BA plus $0.053 \mu \mathrm{MNAA}$

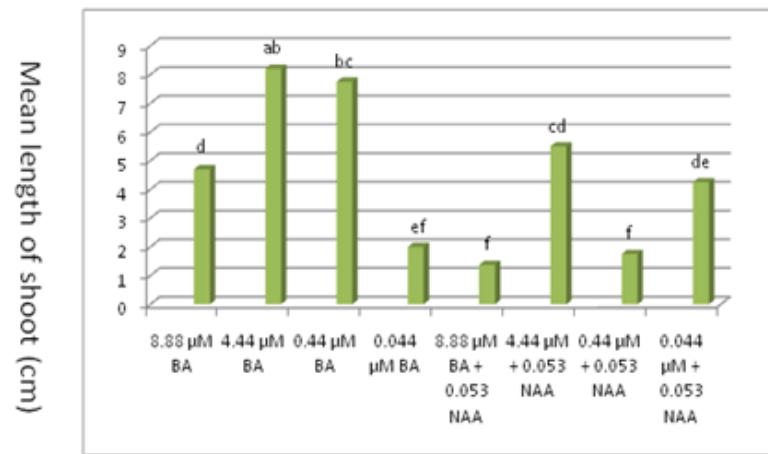

FIG 3. The mean length of multiplicated shoot on medium with $8.88-0.044 \mu \mathrm{M}$ BA and $8.88-0.044$ $\mu \mathrm{M} B A$ and $0.049 \mu \mathrm{M}$ NAA

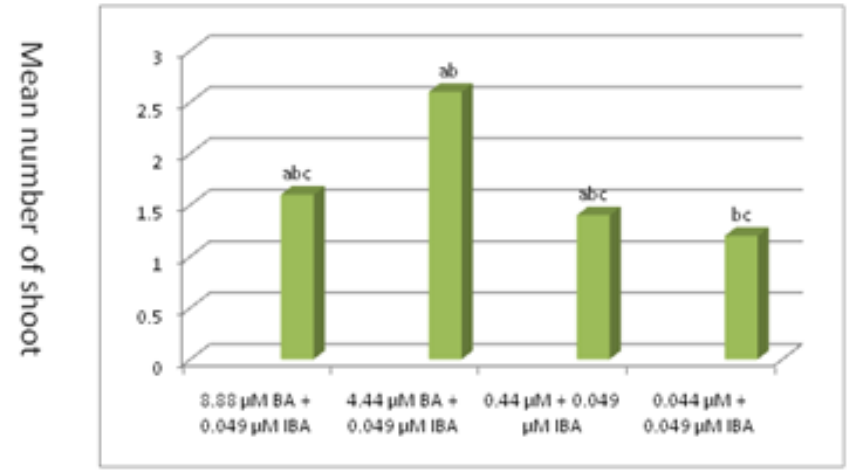

FIG 2. The mean number of multiplicated shoot on medium with $8.88-0.044 \mu \mathrm{M}$ BA and $0.049 \mu \mathrm{M}$ IBA

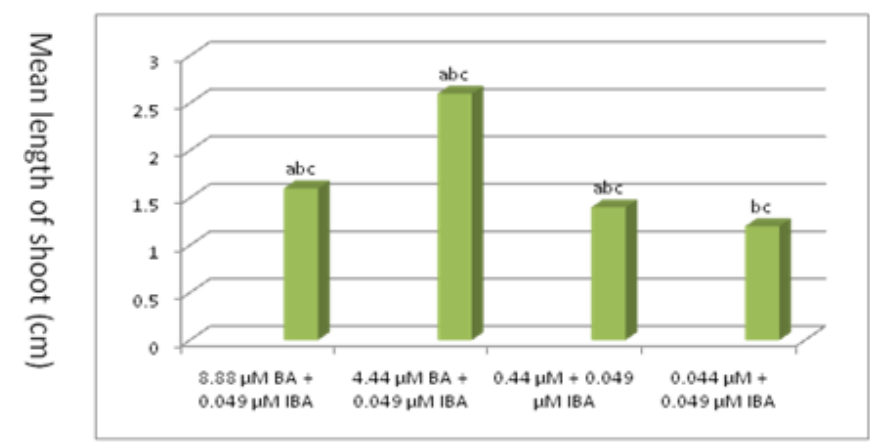

FIG 4. The mean length of multiplicated shoot on medium with $8.88-0.044 \mu \mathrm{M}$ BA and $0.049 \mu \mathrm{M}$ IBA
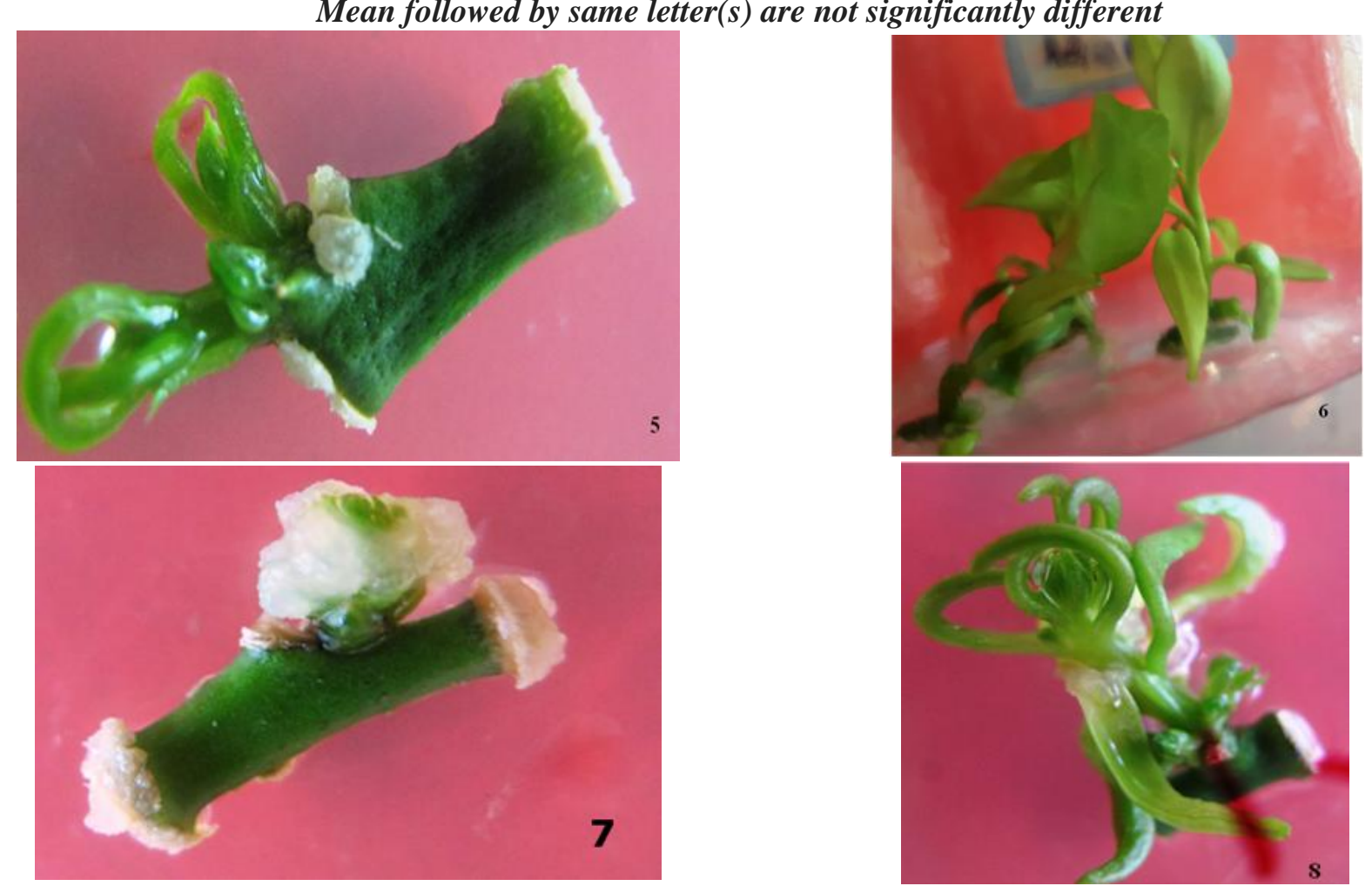

FIGURES 5 - 8. 5 - Multiplicated shoot on medium with 4.44 $\mu \mathrm{M}$ BA and $0.053 \mu \mathrm{M}$ NAA. 6 - Elongation of multiplicated shoot on medium with $4.44 \mu \mathrm{M}$ BA and $0.049 \mu \mathrm{M}$ IBA. 7 and 8 - Multiplicated shoot on medium with $0.44 \mu \mathrm{M}$ BA and $0.049 \mu \mathrm{M}$ IBA 


\section{REFERENCES}

[1] Ahmad N. Faisal M. Anis M. and Aref I.M. 2010. In Vitro callus induction and plant regeneration from leaf explants of Ruta graveolense L. South Afica Journal. 76(3): 597 - 600

[2] Al-Khayri J.M. and Al-Bahrany A.M. 2001. In vitro micropropagation of Citrus aurantifolia (lime). Current Science. 81(9): 1242 1246

[3] Ali S. Mannan A. Oirdi M.E. Waheed A. and Mirza B. 2012. Agrobacterium-Mediated Transformation of Rough Lemon (Citrus jambhiri Lush) with Yeast HAL2 Gene. BMC Research Notes. 5: 285

[4] Bunnag S. and Tangpong, D. 2012. Genetic Transformation of Citrus sinensis L. with an Antisense ACC Oxidase Gene. American Journal of Plant Sciences. 3: 1336 - 1340

[5] Cardoso S.C. Barbosa-Mendes J.M. Boscariol-CamargoR.L. Christiano R.S.C. Filho A.B. Vieira M.L.C. Mendes B.M.J. and Mourao Filho F.A.A. 2010. Transgenic Sweet Orange (Citrus sinensis L. Osbeck) Expressing the Attacin A Gene for Resistance to Xanthomonas citri subsp. citri. Plant Molecular Biology Reports. 28: 185 - 192

[6] Chaudhary M. I. 1994. Fruit Crops. In: Malik M.N. (ed.), Horticulture, 422. National Book Foundation, Islamabad

[7] Doo H. K. Iyyakkannu S. 2016. Influence of benzyladenine and thidiazuron on shoot regeneration from leaf and shoot tip explants of Sedum sarmentosum Bunge. Biological and Applied Sciences. 59: $1-6$

[8] FAO 2001. http://apps.fao.org/lim500/nph-wrap.pl.

[9] Gresser J.W. 1994. In vitro culture of tropical fruits, in plant Cell and tissue culture. Edited by I K Vasil and T A Thorpe (Kluwer Academic Publishers, Dordrecht, The Netherlands). 475 - 496

[10] He Y. Chen S. Peng A. Zou X. Xu L. Lei T. Liu X. and Yao L. 2011. Production and Evaluation of Transgenic Sweet Orange (Citrus sinensis Osbeck) Containing Bivalent Antibacterial Peptide Genes (Shiva A and Cecropin B) via a Novel Agrobacterium-Mediated Transformation of Mature Axillary Buds. Scientia Horticulturae.18: 99 - 107

[11] Kadota M. Lmizu K. and Hirano T. 2001. Double-phase in vitro culture using sorbitol increases shoot proliferation and reduces hyperhydricity in Japanese pear. Scientica Horticulturae. 89(3): 207 - 2015

[12] Komal G. Sharma R. Singh P. K. and Govind S. 2013. Micropropagation of seedless lemon (Citrus limon L. cv. Kaghzi Kalan) and assessment of genetic fidelity of micropropagated plants using RAPD markers. Physiology and Molecular Biology of Plants. 19(1): $137-145$

[13] Lee Y.K. Chung W. Hiroshi E. 2003. Efficient plant regeneration via organogenesis in winter squash (Cucurbita maxima Duch.). Plant Science 164: $413-418$

[14] Mehdi Farshad A. Maheran A.A Nurashikin K. and Ismanizan I. 2014. Effect of cytokinin types, concentrations and their interactions on in vitro shoot regeneration of Chlorophytum borivilianum Sant. \& Fernandez. Electronic Journal of Biotechnology. 17: $275-279$

[15] Munthali M.T. Newburry H.J. Ford-Llyod B.V. 1996. The detection of somaclonal variants of beets using RAPD. Plant Cell Reports. 16: $474-478$

[16] Murashige T. and Skoog F. 1962. A revised medium for rapid growth and bioassays with tobacco tissue cultures. Phyiol. Plant. 15: $473-497$

[17] Nelke M. Nowak I. Wright J.M. McLean N.L. 1993. DNA-based marker techniques to detect somaclonal variations. Plant Cell Reports. 13: 72-78

[18] Perez-Tornero O. Tallon C. I. Porras I. 2010. An efficient protocol for micropropagation of lemon (Citrus limon) from mature nodal segments. Plant Cell Tissue and organ Culture. 100: 263 - 271

[19] Rai G.K. Rai N.P. Kumar S. yadav A. and Rathaur S. 2012. Effects of explant age, germination medium, pre-culture parameters, inoculation medium, $\mathrm{pH}$, washing medium, and selection regime on Agrobacterium-mediated transformation of tomato. In Vitro Cellular and Developmental Biology. 48: 565 - 578

[20] Rathore J.S. Rathore M.S. Singh M. Singh R.P. and Shekhawat N. S. 2006. Micropropagation of mature tree of Citrus limon. Indian Journal of Biotechnology. 6: $239-244$

[21] Salehi M. Nejat N. Tavakoli A.R. and Izadpanah K. 2005. Reaction of Citrus cultivars to Candidatus Phytoplasma aurantifolia In Iran. Iranian Journal of Plant Pathology. 41(3): 363 - 376

[22] Wenuu G. Dingli L. and Yanxin D. 2007. Citrus Transgenic: Current Status and Prospects. Transgenic Plant Journal. 1(1): 202 - 209. 